\title{
Experimental interspecies transmission of plasmacytoid leukemia in salmonid fishes
}

\author{
G. C. Newbound, M. L. Kent* \\ Biological Sciences Branch, Department of Fisheries and Oceans, Pacific Biological Station, Nanaimo, British Columbia, \\ Canada V9R 5K6
}

\begin{abstract}
Plasmacytoid leukemia (PL), also known as marine anemia, has caused high mortalities in chinook salmon Oncorhynchus tshawytscha reared in netpens in the Sechelt area of British Columbia, Canada, since 1988. The cause of the disease is apparently an infectious agent, but the etiology has yet to be determined. Coho salmon $O$. kisutch, Atlantic salmon Salmo salar, rainbow trout $O$. mykiss, and sockeye salmon $O$. nerka are also raised in netpens, and are important to the sport and commercial fisheries. Their susceptibility to PL was therefore investigated. These species, as well as chinook salmon, were exposed to PL by intraperitoneal injection of a kidney homogenate from affected chinook salmon. At 6 to $16 \mathrm{wk}$ post injection (PI), the chinook and sockeye salmon exhibited gross and histological changes consistent with PL. Two of 22 Atlantic salmon also developed histological signs consistent with the disease. The coho and rainbow trout exhibited renal interstitial hyperplasia and foci of cells suggestive of the leukemic plasmablasts in the mesenteries. However, the lesions were mild and the coho and rainbow trout never developed clinical or gross pathological signs of PL. Transmission of PL between different genera and species further supports the hypothesis that the disease is caused by an infectious agent, and not by the transplantation of neoplastic cells. A solid tumor composed of plasmablasts was observed in the swimbladder of one exposed sockeye. This is additional evidence that the disease is a neoplastic condition rather than a reactive plasmacytosis.
\end{abstract}

\section{INTRODUCTION}

A plasmacytoid leukemia (PL) of chinook salmon Oncorhynchus tshawytscha, often referred to as marine anemia, has been diagnosed at several seawater netpen farms in the Sechelt area of British Columbia (B.C.), Canada, since 1988 (Kent et al. 1990). In the field, the disease is first observed in fish after they have been in seawater for ca $1 \mathrm{yr}$, where it persists in the affected populations until the fish are utilized, either for production 6 mo later, or as broodstock 1 to $3 \mathrm{yr}$ later. PL has been diagnosed for the last 3 consecutive years in chinook salmon introduced to seawater in 1987, 1988, and 1989. This disease has occurred in at least 17 sites, and mortality was ca $80 \%$ (46000 fish) at one site. The economic importance of the disease to the aquaculture industry is therefore significant, particularly because it affects large fish with a high individual value.

The disease is characterized by the pallor of gills, splenomegaly, renomegaly, exophthalmos, and an

\footnotetext{
- Addressee for correspondence
}

accumulation of hemocoelemic fluid. Histologically, there is massive infiltration of the kidney with cells suggestive of immature plasma cells (plasmablasts) (Kent et al. 1990). These cells are also seen in abnormal numbers in the spleen, perivascular and periportal areas of the liver, periorbital areas, lamina propria of the gut, and in the peripancreatic tissue. Although the etiology of PL is not known, Kent \& Dawe (1990) have demonstrated that the cause is most likely an infectious agent. They suggested that the etiology may be an oncogenic virus (e.g. a retrovirus), primarily because infectious hemic neoplasia in both fishes and other vertebrates are often caused by these agents and because no other agent was consistently associated with the disease.

Oncogenic retroviruses are not strictly host specific. For example, bovine leucosis virus (BLV) can also infect sheep and can cause lymphosarcomas as well as leukemias in both species (Burny et al. 1980). This virus has also been shown to infect, in vitro, cells of human, simian, canine, bovine, caprine, ovine, and bat origin (Graves \& Ferrer 1976, Todaro 1980).

In the field, PL has only been observed in chinook 
salmon. Other salmonid fishes are also economically important to the aquaculture industry and the commercial and sports fisheries. Atlantic salmon Salmo salar, coho salmon Oncorhynchus kisutch, rainbow trout (steelhead) O. mykiss, and, more recently, sockeye salmon $O$. nerka, are all being raised in netpens. All of these fishes are important to fisheries in British Columbia, with sockeye being the most economically important in the wild salmonid fisheries (Leitz 1988). Thus, it is important to ascertain whether other salmonid species are susceptible to PL. Kent \& Dawe (1990) reported briefly on interspecies transmission of PL to various salmonid fishes. We describe here in detail the gross and histopathological changes in various salmonid fishes experimentally exposed to PL.

\section{MATERIALS AND METHODS}

Salmonid fishes showing no signs of PL were collected from freshwater hatcheries in B.C. and maintained at the Pacific Biological Station, Nanaimo, B.C., Canada. Fourteen chinook salmon (average weight $46 \mathrm{~g}$ ), 24 Atlantic salmon (avg. wt $21 \mathrm{~g}$ ), 25 sockeye salmon (avg. wt $37 \mathrm{~g}$ ), 24 coho salmon (avg. wt $20 \mathrm{~g}$ ), and 26 rainbow trout (avg. wt $45 \mathrm{~g}$ ), were used as recipient fishes. These fishes were exposed to PL by an intraperitoneal injection of affected kidney tissue. Three chinook salmon with PL were sacrificed, and their kidney tissues were pooled and diluted 1:4 in Minimum Essential Medium (MEM). The preparation was then thoroughly homogenized with a Polytron (Brinkman Instruments, Westburg, NY, USA). Wet mount preparations of the homogenate were examined to ensure that no intact cells survived homogenization. The recipient fishes were then anaesthetized with MS222 (tricaine methane sulfonate, Syndel Laboratories, Nanaimo, B.C.), and injected intraperitoneally (IP) with $0.5 \mathrm{ml}$ of the homogenate.

Two groups of controls were used for each species The first was injected with MEM (0.5 ml IP fish $\left.{ }^{-1}\right)$ These fishes were examined at $10 \mathrm{wk}$ after injection The second group of controls were injected with a kidney homogenate prepared from 3 chinook without PL. The kidney tissue of the donor fish used for the PL exposed group was also infected with Renibacterium salmoninarum, the causative agent of bacterial kidney disease (BKD). This agent is widespread in salmon farms in British Columbia and frequently occurs in association with PL. Therefore, to minimize the differences between the control and PL-exposed groups, kidneys infected with $R$. salmoninarum were used for this control inoculum. Ten fish of each species were used in each control group.

All fishes were maintained in open system fresh- water tanks at $10^{\circ} \mathrm{C}$ prior to injection. They were then acclimated to brackish seawater (salinity ca $20 \mathrm{ppt}$ ) at 9 to $10^{\circ} \mathrm{C}$. The experimental fishes were kept together in one tank, and the controls in 2 other tanks. The experimental fishes were sacrificed in 2 groups; one at $10 \mathrm{wk}$ post injection and another at $16 \mathrm{wk}$ PI. Moribund and dead fish were also examined throughout the study. All fishes were examined for gross pathological changes. Posterior kidney, spleen, pyloric caeca and associated mesentery and pancreas, posterior intestine and liver were collected and preserved in Davidson's solution. Any other abnormal-looking tissues were also sampled. These samples were prepared for histological examination and stained with hematoxylin and eosin using standard procedures.

Kidney and peripancreatic tissues of a sockeye salmon with PL were prepared for electron microscopy. Tissues were fixed in $4 \%$ glutaraldehyde in Milloning's phosphate buffer, post-fixed in $1 \% \mathrm{OsO}_{4}$, embedded in Epon plastic, sectioned, stained with lead citrate and uranyl acetate, and examined with a transmission electron microscope.

\section{RESULTS}

Within $24 \mathrm{~h} \mathrm{PI}, 1$ coho and 2 Atlantic salmon died, most likely due to stress from anaesthesia and handling. Morbidity was first observed in the chinook (at $42 \mathrm{~d} \mathrm{PI}$ ), and gross and histopathological examination confirmed the presence of PL. Nine of the exposed 14 chinook died before the first sampling at $10 \mathrm{wk}$ PI. All of these fish exhibited both gross and histological changes consistent with severe PL. The results of both sacrifices, one at $10 \mathrm{wk} \mathrm{PI}$, and the other at $16 \mathrm{wk}$ PI, are shown in Table 1. The chinook and sockeye salmon were the most severely affected species, and showed the highest incidence of PL. However, the sockeye salmon appeared to be less anemic than the chinook, based on pallor of the gills, and at $10 \mathrm{wk}$ showed no lethargy, which is commonly associated with clinical PL in chinook. Additionally, the kidneys of the sockeye were not as swollen as those of the chinook, and the sockeye salmon, unlike the chinook, did not exhibit ascites. Histological examination of the sockeye revealed renal interstitial hyperplasia and an accumulation of plasmablasts in the spleen, liver, mesenteries, gut, and occasionally heart and periorbital tissue. In contrast to the chinook, necrosis was also a prominent feature of PL in the sockeye salmon. Macrophages replete with necrotic tissue debris were consistently observed in blood vessels in association with the proliferating plasmablasts (Fig. 1).

The plasmablasts of the sockeye salmon were similar in morphology to chinook plasmablasts previously 
Table 1. Incidence of plasmacytoid leukemia (PL) in chinook salmon Oncorhynchus tshawytscha, sockeye salmon $O$. nerka, and Atlantic salmon Salmo salar, and incidence of PL-like lesions in rainbow trout $O$. mykiss and coho salmon $O$. kisutch exposed to a PL-affected tissue homogenate

\begin{tabular}{|lcccc|}
\hline Species & 10 wk PI $^{\triangleleft}$ & 16 wk PI & Moribund & Total \\
\hline Atlantic salmon & $1 / 10(10)^{1}$ & $0 / 8(0)$ & $1 / 4(25)$ & $2 / 22(9)$ \\
Chinook salmon & $5 / 5(100)$ & $0 / 0(0)$ & $9 / 9(100)$ & $14 / 14(100)$ \\
Coho salmon & $8 / 10(80)$ & $1 / 13(8)$ & None & $9 / 23(39)$ \\
Rainbow trout & $1 / 11(9)$ & $4 / 15(27)$ & None & $5 / 26(19)$ \\
Sockeye salmon & $11 / 11(100)$ & $3 / 3(100)$ & $4 / 11(36)$ & $18 / 25(72)$ \\
a PI: post injection & & & & \\
b Affected/sampled $(\%)$ & & & & \\
\hline
\end{tabular}

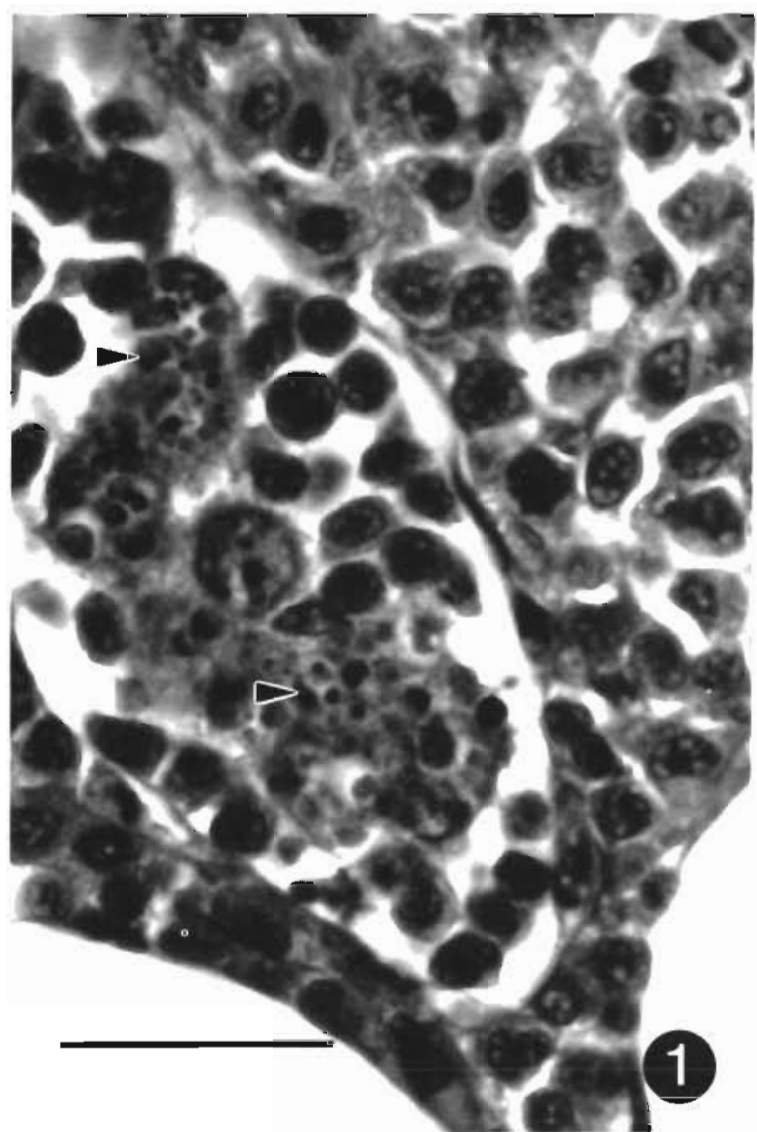

Fig. 1. Oncorhynchus nerka. Plasmablasts in a pancreatic vein, with perivascular infiltration of plasmablasts (P). Arrowheads = intravascular necrotic debris. $\mathrm{H} \& \mathrm{E}, \mathrm{bar}=25 \mu \mathrm{m}$

described (Kent et al. 1990), except that many appeared to be more mature. In comparison to the plasmablasts of chinook, many of those of the sockeye showed an increase in clumped chromatin and eccentric nuclei. Also, in some cells a clear Golgi zone was visible. Electron microscopy demonstrated the plasma cell characteristics of these cells. They contained abundant, well-organized rough endoplasmic reticulum, prominent Golgi zones, eccentric nuclei, and distinct clumped chromatin (Fig. 2).

One of the sockeye salmon had a $2 \mathrm{~cm}^{3}$ mass in the swimbladder that extended dorsally to the posterior kidney (Fig. 3). The mass exhibited transmural infiltration through the swimbladder and was comprised of plasmablasts, with occasional macrophages and lymphocytes. The cells were arranged in whorls with a small amount of stroma and a preponderance of blood vessels. The plasmablasts had a high mitotic index.

Two of 22 exposed Atlantic salmon exhibited PL. These had renal interstitial hyperplasia and showed an infiltrate of the plasmablasts in the mesenteries (Fig. 4). One of these Atlantic salmon also exhibited the plasmablasts throughout the lumen of the ventricle of the heart and an infiltrate into the epicardium. The other had an infiltrate of the plasmablasts into the epaxial muscles adjacent to the posterior kidney.

The coho and the rainbow trout showed histological changes different to those of the affected sockeye, chinook and Atlantic salmon. The coho and rainbow trout showed renal interstitial hyperplasia consisting of a mixed population of hemoblasts, as well as an infiltrate of plasmablasts into the mesentery and peripancreatic fat (Fig. 5). In contrast to the sockeye and chinook, the mesenteric infiltrate was mild, and the massive infiltration into the reticuloendothelial (RE) organs or alimentary tract was lacking. None of the coho or rainbow trout died or were collected as moribund during this study.

Some of the exposed fishes exhibited gross and histological signs of BKD (Table 2). Both PL-positive and -negative fish developed signs of $\mathrm{BKD}$. The histological changes due to $B K D$ in all species were consistent with previous reports of BKD (Bruno 1986), and were characterized by random, multifocal pyogranulomatous nephritis, hepatitis, splenitis, epicarditis, and coelomitis, with macrophages replete with small bacilli.

The control fishes that were injected with a kidney homogenate were sacrificed at $8 \mathrm{wk}$ instead of $10 \mathrm{wk}$ because they were dying of BKD. None of these fishes 


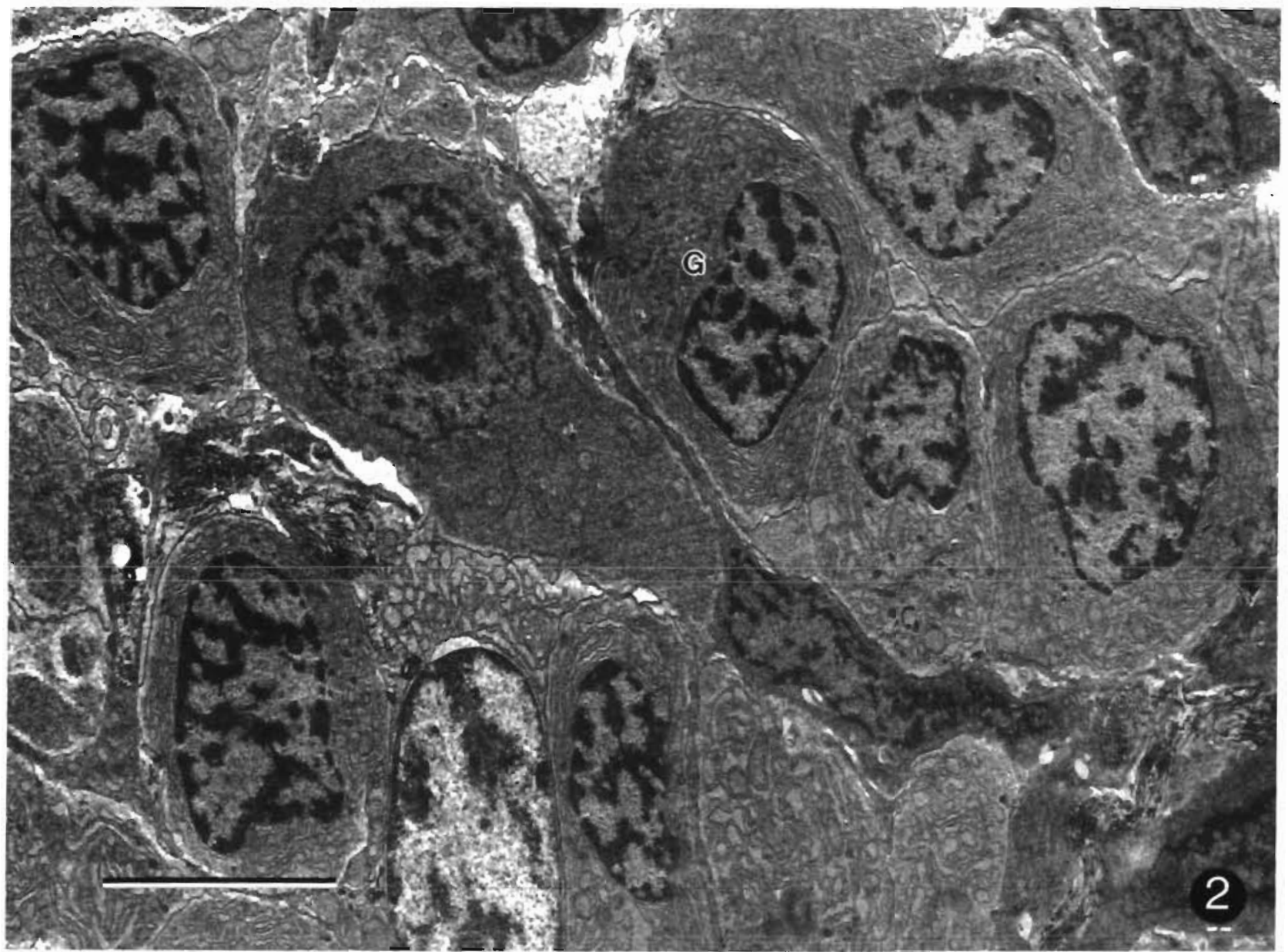

Fig. 2. Oncorhynchus nerka. Electronmicrograph of plasmablast in the kidney interstitium of a fish with PL. Note abundant rough endoplasmic reticulum and Golgi zone (G). Bar $=5 \mu \mathrm{m}$

showed any of the lesions suggestive of PL, but BKD was confirmed histologically in all of these fishes. In addition, the control coho and rainbow trout showed no mesenteric inflammatory infiltrates as seen in the PLexposed coho and rainbow trout, except when associated with Renibacterium salmoninarum.

Control fishes injected with MEM only and sacrificed at $10 \mathrm{wk}$ PI showed no histological evidence of PL or $\mathrm{BKD}$, indicating that the stocks used in the study were free of these diseases.

\section{DISCUSSION}

All of the chinook and 18/25 of the sockeye exhibited unequivocal gross and histopathological changes consistent with PL. The 7 sockeye collected as moribund were so severely affected with BKD that we could not determine if these fish also had PL. It would thus appear that sockeye salmon are very susceptible to $\mathrm{PL}$, at least by experimental transmission. There were 2 consistent differences between the histopathological changes of the sockeye and chinook. In the sockeye there were many macrophages with engulfed cellular debris, and the proliferating plasmablasts of the sockeye often appeared more mature. The morphological features of these cells, as determined by electron microscopy, further support the conclusion that the cells are of the plasma cell lineage. The origin of the necrotic cellular debris was not determined. However, the increase of necrosis in the sockeye may be associated with a possible increase in the turnover of the plasmablasts, which in sockeye salmon appeared to be more mature cells.

One of the limitations with using histology for the diagnosis of PL is that $\mathrm{BKD}$ has become a confounding variable because the large granulomas and other inflammatory changes in RE tissue and mesenteries may mask the presence of the proliferating plasmablasts. At this time, confirmatory diagnosis of PL is only achievable by histological examination of severely infected fishes. Therefore, due to the crude- 


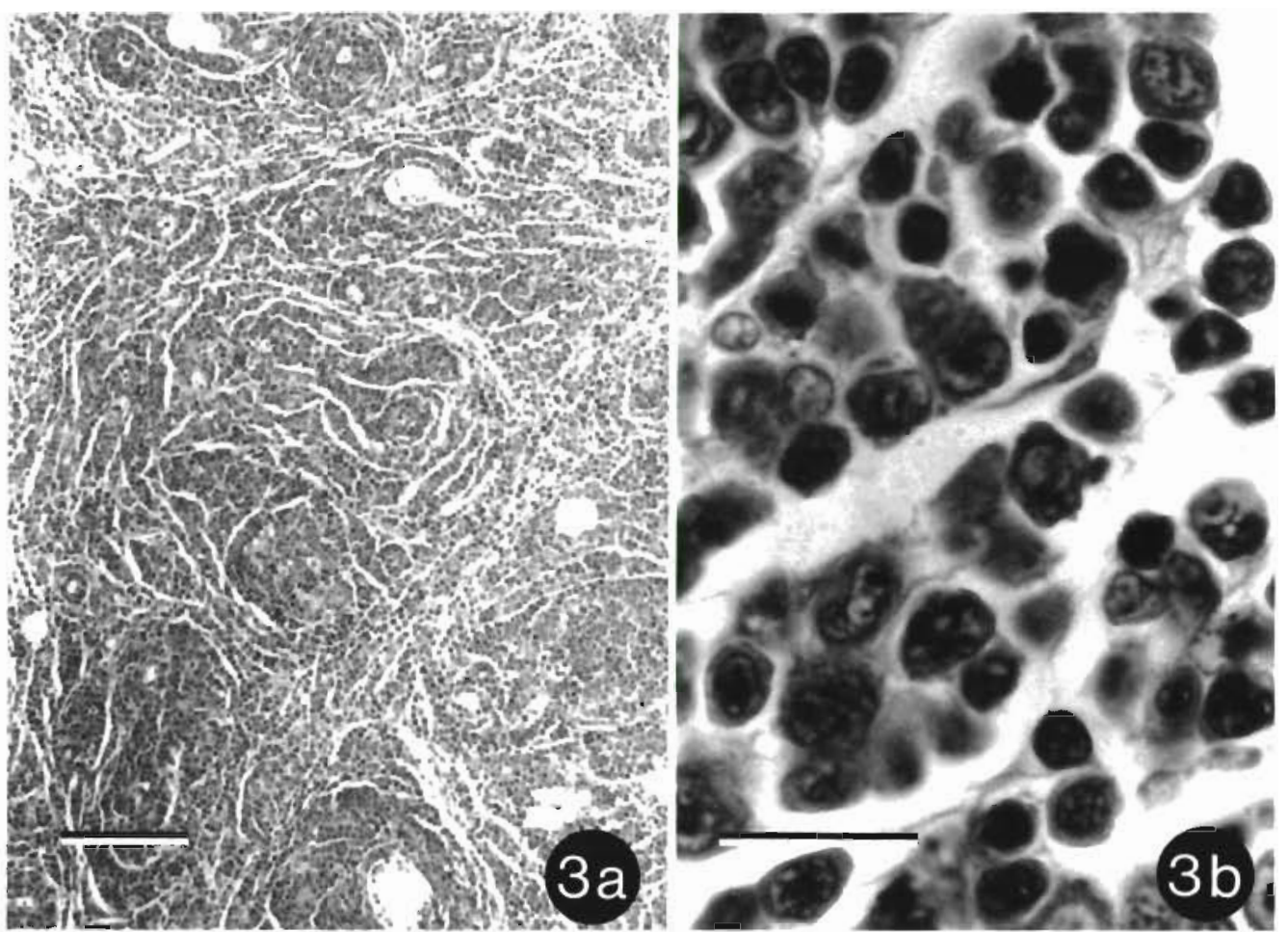

Fig. 3. Oncorhynchus nerka. Swimbladder tumor in fish with PL. (a) Low magnification showing whorls of plasmablasts; H \& E, bar $=1 \mathrm{~mm}$. (b) High magnification showing prollferating plasmablasts; $\mathrm{H} \& \mathrm{E}_{;}$bar $=25 \mu \mathrm{m}$

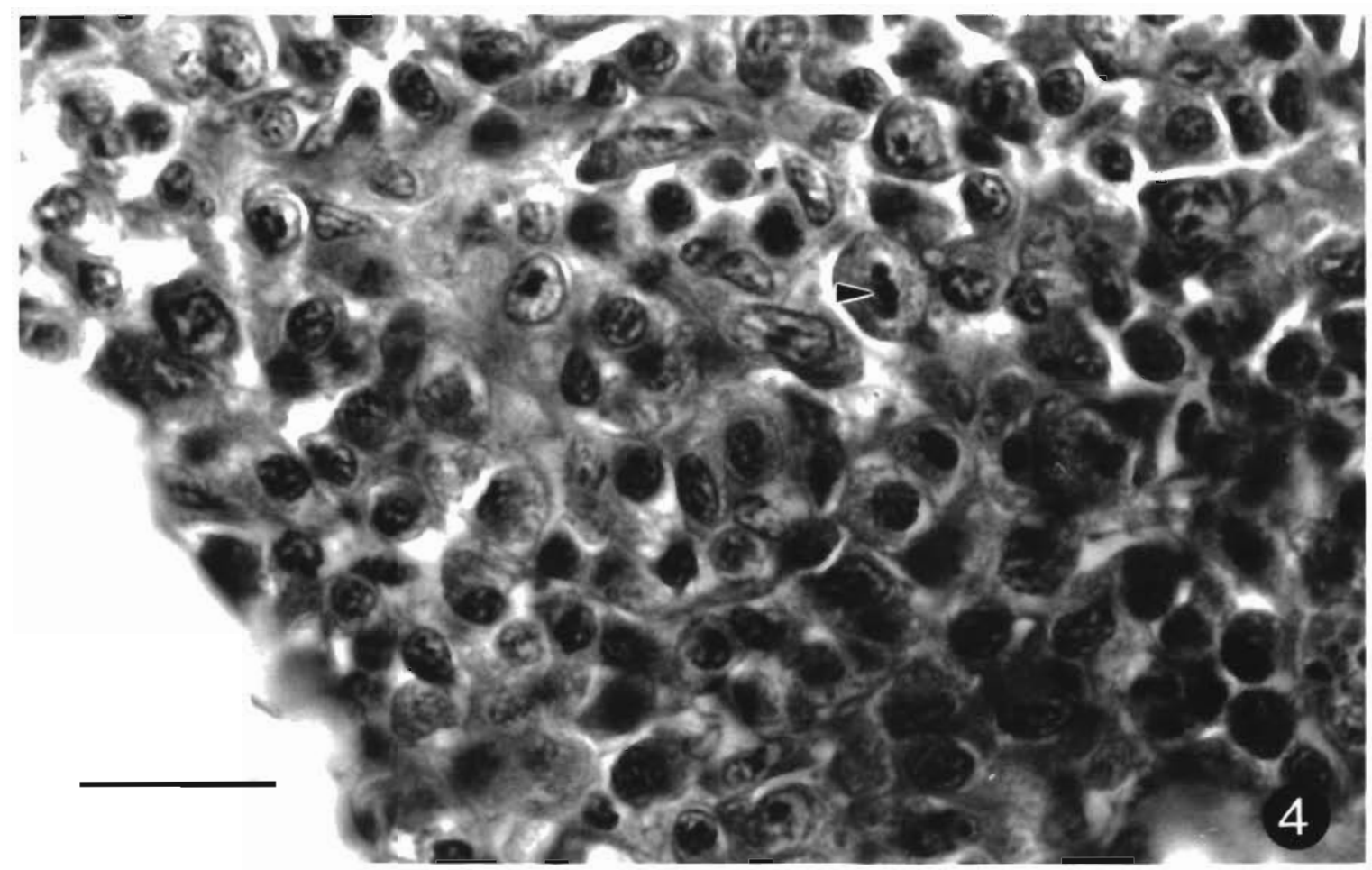

Fig. 4. Salmo salar. Proliferating plasmablasts in the peripancreatic tissue. Arrowhead $=$ mitotic figure. $\mathrm{H} \& \mathrm{E}_{;}$bar $=20 \mu \mathrm{m}$ 


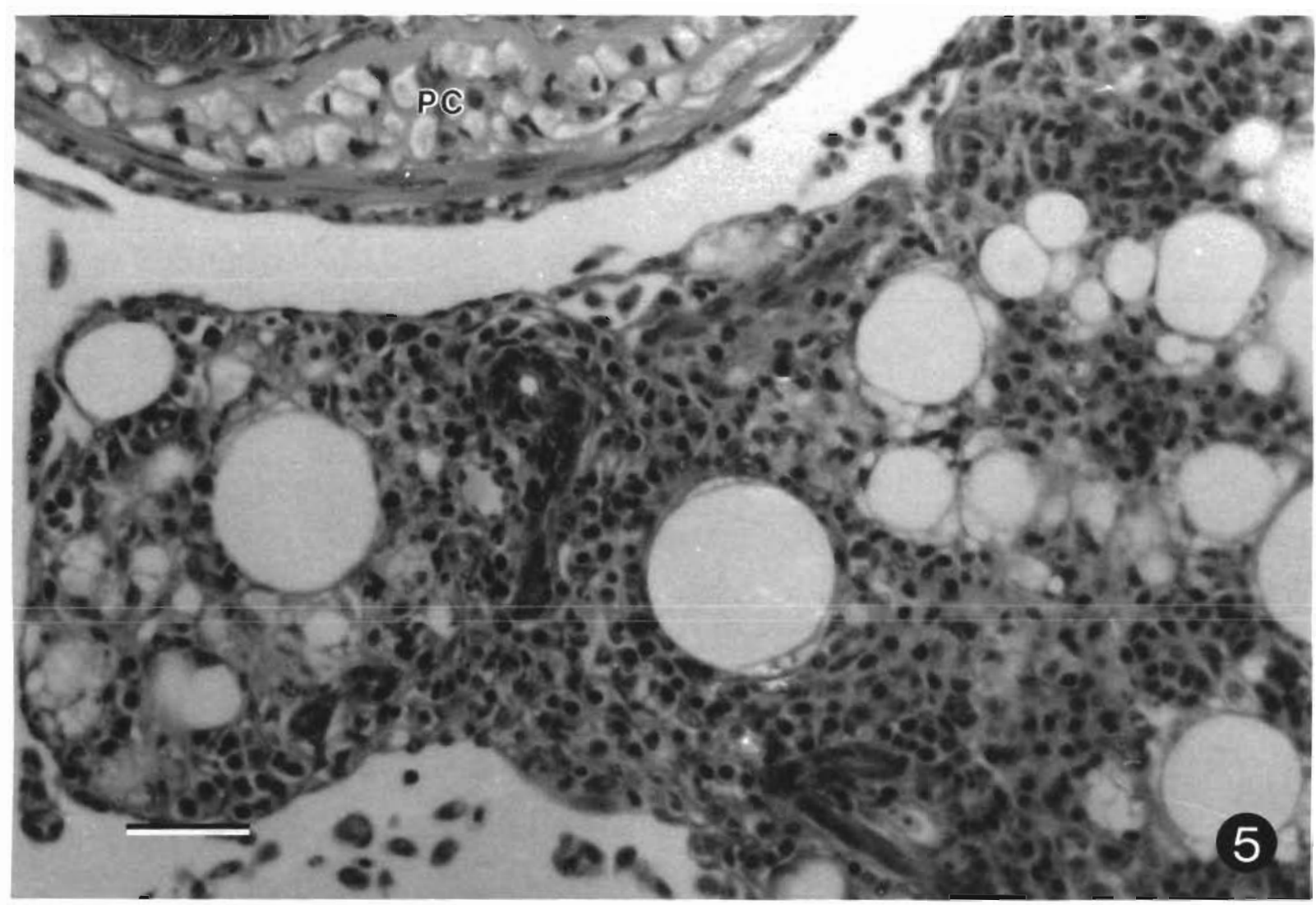

Fig. 5. Oncorhynchus kisutch. Proliferating plasmablasts in mesenteries of the pyloric caeca (PC). H \& $E_{i}$ bar $=100 \mu m$

Table 2. Association of bacterial kidney disease (BKD) with plasmacytoid leukemia (PL) in fishes experimentally exposed to PL

\begin{tabular}{|lccccc}
\hline Species & $\begin{array}{c}\text { No. fish } \\
\text { examined }\end{array}$ & BKD+ and PL- & BKD + and PL+ & Number: \\
\hline Atlantic salmon & 22 & 14 & 2 & 0 & BKD-and PL- \\
Chinook salmon & 14 & 0 & 5 & 9 & 6 \\
Coho salmon & 23 & 3 & 1 & 8 & 0 \\
Rainbow trout & 26 & 2 & 10 & 8 & 11 \\
Sockeye salmon & 25 & 7 & 0 & 0 \\
\hline
\end{tabular}

ness of our detection methods, we have no way of determining if a mildly affected fish is infected with the etiologic agent of $\mathrm{PL}$, or is responding to another agent.

Both the PL-positive and -negative donor fish were infected with Renibacterium salmoninarum, and this would account for BKD in both the exposed and control fishes (Table 2). These controls were sacrificed early in an attempt to collect fish before severe BKD masked the possible presence of proliferating plasmablasts. In experimentally induced infections, the time to morbidity and mortality due to BKD is a function of the dose of the bacteria administered (Bell et al. 1984). Therefore, the fact that the homogenate-injected controls had to be prematurely sacrificed was probably due to a higher concentration of $R$. salmoninarum in this preparation than in the PL homogenate.

Agents that induce chronic inflammation may be cofactors for plasmacytomas in higher animals (Potter 1972) and it is possible that Renibacterium salmoninarum serves as a cofactor for PL. However, as seen in the present study (Table 2), in previous transmission studies (Kent \& Dawe 1990), and from netpen epizootics (Kent et al. 1989, J. B. Brackett, Syndel Laboratories, Nanaimo, B. C., pers. comm. 1990), some fish can have $\mathrm{PL}$ in the absence of $R$. salmoninarum infections or BKD. This suggests that $R$. salmoninarum is not a required cofactor for PL. 
The occurrence of a large solid tumor comprised of plasmablasts in the swimbladder of one of the sockeye strongly supports the hypothesis that PL is a neoplastic disease. The mass possessed many of the characteristics of a true neoplasm suggestive of a malignant tumor (Thomson 1984): it invaded the surrounding tissue and was poorly circumscribed; it was comprised of mitotically active, undifferentiated plasmablasts; and it contained few other inflammatory cells. The tumor, therefore, appeared to have resulted from uncontrolled growth of a single cell line.

The present study demonstrated transmission of PL between genera (with Atlantic salmon) and between species of the same genus (with sockeye salmon). This further supports the assumption that the disease is caused by an infectious agent, as opposed to the transplantation of neoplastic cells. Sakai (1982) has shown that the allogenic transfer of lymphocytes is possible between trout that are not syngenic. He also demonstrated that the transfer of lymphocytes between different species in the genus Oncorhynchus was not possible, presumably due to a host versus graft reaction. The species used for these trials were Oncorhynchus mykiss, $O$. nerka and $O$. masou. Because we used healthy, apparently immunocompetent fishes in this study, we conclude that a host versus graft reaction would have eliminated any intact chinook plasmablasts in the sockeye and Atlantic salmon, and that the proliferating plasmablasts were of host origin. Also, no evidence of intact cells was found in the homogenates. Therefore, PL in these fishes must be due to an infectious agent, as opposed to the transplantation of neoplastic cells.

Only 2 of 22 exposed Atlantic salmon developed PL, indicating that they are more resistant to PL than chinook or sockeye. The coho and rainbow trout also appeared to be resistant to PL. In the case of the coho, $80 \%$ of the first sacrifice exhibited mild changes suggestive of PL, whereas only $8 \%$ exhibited changes in the second sacrifice. A likely explanation for this is that the coho became infected with the agent causing PL, showed mild proliferative changes, and then recovered at $16 \mathrm{wk}$. Thus the changes in this species may represent an early proliferative response that does not develop into neoplasia. The trout exhibited similar histological changes to the coho, except that the lesions were more prevalent at $16 \mathrm{wk}$ than at $10 \mathrm{wk}$. Perhaps the course of the infection is longer in the trout than the other species, and had we not terminated the experiment, these fish may have become clinically diseased at some later date. However, the delay in the proliferation of the plasmablasts in this species is an indication of resistance to PL. It is unlikely that these mild changes in the coho and rainbow trout are inflammatory responses due solely to injection of kidney tissue or
Renibacterium salmoninarum because the control fish that were also injected with a kidney homogenate containing $R$. salmoninarum did not exhibit these changes. Furthermore, with the rainbow trout, it is unlikely that inflammation would persist in the same form and at a similar prevalence at 10 and $16 \mathrm{wk}$ (Table 2).

Because the coho and rainbow trout exhibited only mild proliferative changes, and none of these fishes ever showed clinical, gross or full histological changes consistent with PL, we conclude that these 2 species are not susceptible to $\mathrm{PL}$, at least by this experimental method of transmission.

The occurrence of PL in sockeye and Atlantic salmon further emphasizes the importance of this disease. The commercial fishery in B.C. relies heavily on wild sockeye salmon, and many farms are starting to rear sockeye in netpens. The culture of Atlantic salmon is already well established in B.C. The economic significance of $\mathrm{PL}$ is still not fully realized. Although many farms have lost a great number of chinook to PL, decrease in feed conversion and growth associated with PL may even be more important economic factors than fish losses.

We have demonstrated that sockeye and Atlantic salmon are susceptible to PL by IP injection, but it is unknown whether these fishes are susceptible in the netpen environment. Assessment of the susceptibility of these species in both the wild and netpen environments are presently underway. Studies to elucidate the etiology of PL are also in progress.

Acknowledgements. This study was supported in part by the Ministry of Agriculture and Fisheries. Commercial Fisheries and Aquaculture Branch, Province of British Columbia, Canada. The authors thank S. Dawe for histological sections, J. Bagshaw for electron microscopy preparations, and Dr I' Evelyn for manuscript review.

\section{LITERATURE CITED}

Bell, G. R., Higgs, D. A., Traxler, G. S. (1984). The effect of dietary ascorbate, zinc, and manganese on the development of experimentally induced bacterial kidney disease in sockeye salmon (Oncorhynchus nerka). Aquaculture 36: 293-311

Bruno, D. W (1986) Histopathology of bacterial kidney disease in laboratory infected rainbow trout, Salmo gairdneri Richardson, and Atlantic salmon, Salmo salar L., with reference to naturally infected fish. J. Fish Dis. 9: 523-527

Burny, A., Bruck, C., Chantrenne, H., Cleuter, Y., Dekegel, D., Ghysdael, J., Kettmann, R., Leclercq, M., Leunen, J., Mammerickx, M., Portelle, D. (1980). Bovine leukemia virus: molecular biology and epidemiology. In: Klein, G. (ed.) Viral oncology. Raven Press, New York, p. 231-288

Graves, D. C., Ferrer, J. F. (1976). In vitro transmission and propagation of the bovine leukemia virus in monolayer cell cultures. Can. Res. 36: 4152-4159 
Kent, M. L., Dawe, S. C. (1990). Experimental transmission of a plasmacytoid leukemia of chinook salmon, Oncorhynchus tshawytscha. Can. Res. (Suppl). 50: 5679-5681

Kent, M. I., Groff, J. M., Traxler, G. S., Zinkl, J. G., Bagshaw, J. W. (1990). Plasmacytoid leukemia in seawater reared chinook salmon Oncorhynchus tshawytscha. Dis. aquat. Org. 8: 199-209

Kent, M. L., Traxler, G. S., Bagshaw, J. W., McKay, J. A. (1989). A hemic proliferative disorder associated with severe anemia in pen-reared chinook salmon, Oncorhynchus tshawytscha. Am. Fish. Soc./Fish Health News 17 (2): 7

Leitz, P. (1988). Fish product exports of British Columbia,

Responsible Subject Editor: N. Peters, Hamburg, Germany
1988. Pacific region. Department of Fisheries and Oceans, Vancouver, B. C. Canada

Potter, M. (1972). Immunoglobulin-producing tumors and myeloma proteins of mice. Phys. Rev. 52: 631-719

Sakai, D. K. (1982). Transferability of an ability to synthesize hemolytic antibodies in the allogenic lymphocyte transfer of rainbow trout. Bull. Jap. Soc. scient. Fish. 48 (7) 911-916

Thomson, R. G. (1984). General veterinary pathology. W. B. Saunders Co., Toronto

Todaro, G. J. (1980). Interspecies transmission of mammalian retroviruses. In: Klein, G. (ed.) Viral oncology, Raven Press, New York, p. 291-309

Manuscript first received: November 19, 1990 Accepted: January 28, 1991 